\title{
An Analysis of the Determinants of Fertility Differentials Amongst the Poorest Women Population in Kenya
}

\author{
Robert Mathenge Mutwiri \\ Department of Physical sciences, Kirinya University, Kerugoya, Kenya \\ Email address: \\ mutwiri@outlook.com
}

\section{To cite this article:}

Robert Mathenge Mutwiri. An Analysis of the Determinants of Fertility Differentials Amongst the Poorest Women Population in Kenya. International Journal of Statistical Distributions and Applications. Vol. 5, No. 3, 2019, pp. 60-66. doi: 10.11648/j.ijsd.20190503.13

Received: July 2, 2019; Accepted: July 27, 2019; Published: August 13, 2019

\begin{abstract}
Fertility is one of the major elements in population dynamics that has the highest significant contribution towards population size and structure in the world. In Kenya, fertility levels have been on the decline from approximately 8.1 children in 1979 to 3.9 children in 2014 but still, it is considered high compared to the country's target of 2.6 by 2030 . This has potentially negative consequences to the economic growth and development of a country. The main objective of this study is to determine demographic, socio-economic and cultural factors that explain fertility differential among poor women of childbearing age. A binary logistic regression model was fitted to DHS 2014 data using SPSS Version16. The total number of women in childbearing age is based on 7,262 women who have at least one child and whose age ranges from 15 to 49 years. The majority of women were married 4685 (64.5\%), followed by never and formally married $1522(21.0 \%)$ and living with partner 1055 (14.5\%) respectively). In the analyses, all the variables Region, women educational level, marital status, age at first marriage and age in 5-years group were found to have a significant effect on the total number of children ever born at a significance level of $5 \%$. From the fitted logistic regression model, the estimated odds ratio for the variable region reference category is Nyanza/Western region. The value of the odds ratio $\exp (\beta)=1.060775$, for the region that the odds of having TCEB greater than or equals to five children for the North Eastern region has $6.0775 \%$ more than women in Nyanza/Western Region $(\mathrm{OR}=1.060775, \mathrm{C} . \mathrm{I}=0.873716-1.287883)$ and its effect is statistically significant.
\end{abstract}

Keywords: Fertility Levels, Binary Logistic Regression Model, DHS Data, Total Fertility Rate

\section{Introduction}

The total fertility rate (TFR) in Kenya has decreased significantly from 8 births per women in the 1970 s to 3.9 births per women in 2014. At 3.9, the country has not achieved its set target of 2.6 [28]. Total fertility rates, as well as fertility decline rates have not been even among all the wealth quintiles. For in instance, the TFR among the poorest wealth quintile was $7.2,6.5,7.6,7.0$, and 6.4 in 1993, 1998, $2003,2008 / 9$, and 2014 respectively while the richest wealth quintile had a TFR of 3.3, 3.0, 3.1, 2.9, and 2.8 in 1993, 1998, 2003, 2008/9, and 2014 respectively. Percentage decline in fertility from 1993 to 2014 is lowest among poorest wealth quintile (11 percent) compared to other wealth quintiles (23 percent; 32 percent; 42 percent; and 15 percent) [25]. Notably, the fertility among the poorest wealth quintile has been more than twice the fertility among the richest wealth quintile in all the surveys conducted under DHS series in Kenya (NCPD, 2013).

Alaba, Olubusoye and Olaomi [2] used the geoaditive Bayesian model based on Negative Binomial distribution as a measure of overdispersion to investigate the spatial determinants of fertility differentials in Nigeria. Majumder and Ram [23] investigated the role of proximate determinants on fertility decline among poor and non-poor in Asian countries. Awes [4] conducted a similar study in Kenya, on the role of proximate determinants of fertility inhibiting effects among the poor and non-poor of Kenya over the period 2003 and 2008/09. Anyara and Hinde [3] conducted a regional analysis of fertility patterns in Kenya since 1989 using data from the four Demographic and Health Surveys of 1989, 1993, 1998 and 2003. Muhoza, Broekhuis and Hooimeijer [24] fitted a logistic regression to investigate the effects of wealth, education, religious affiliation and place of residence on the desired family size and excess fertility in East Africa. Dana [10] fitted binary logistic regression model 
to Ethiopians DHS data and found that Age at first marriage, residence, woman's education level, region, use of contraceptives determined the total number of children ever born to a woman in Ethiopia. Adhikari [1] fitted a linear regression model to the Nepalese DHS data and found that the age at first marriage, perceived ideal number of children, place of residence, literacy status, religion, mass media exposure, use of family planning methods, household headship, and experience of child death were the most important variables that explained the variance in fertility. Their study found an inverse relationship between wealth status and fertility, with significantly lower fertility among the richest women compared to high fertility among the poorest. Similar findings have been reported in $[11,32]$ and [27]. Many other previous studies have focused on the sociocultural and economic determinants of fertility in various regions [11, 13, 14, 18, 23, 24, 27, 29, 32, 34, 35].

Despite the numerous studies on fertility, fertility differentials and its determinants in Kenya, little or nothing is known about the most affected poor women based on the wealth index quintile classification. In particular, the linkage between fertility and poverty has not been fully explored. Most studies in Kenya have looked at the socioeconomic determinants of fertility by examining the differentials in education [31] and urban rural fertility differentials [37]. Therefore this study will strive to understand the fertility differentials among the poor womens in Kenya and the factors leading to fertility differentials using the Bongaarts analytical model of 1978 .

This paper is organized as follows: Section 2 gives the source of data and methodology including a brief overview of logistic regression. Section 3 provides data analysis and discussion of results. Section 4 ends the paper with some concluding remarks.

Objectives of the study

The main objective of this study is to identify Demographic, Socio-economic, and Cultural factors that affect Fertility level among women of childbearing age in Kenya.

Specific objectives

1. To identify the factors which have significant effect on the fertility of the respondent.

2. To develop statistical model that predicts the fertility among women of childbearing age based on knowledge of the identified factors.

3. To provide information based on this study to researchers and policy makers.

\section{Materials and Methods}

\subsection{Data Source}

This study has utilized data obtained from the 2014 Kenya Demographic and Health Survey (KDHS). The 2014 Kenya
Demographic and Health Survey (KDHS) is a nationally representative sample survey that targeted 40,300 households in all of the 47 counties in Kenya, with an aim of collecting data on different aspects of population and health in the country. Each of the 47 counties in the country was stratified into urban and rural strata. There were 1,612 clusters spread across the whole country, with 995 clusters in rural areas and 617 in urban areas. The survey interviewed 31,079 women aged 15-49. Out of these 14,741 were interviewed for the full women questionnaire and 16,338 for the short woman questionnaire. The 2014 KDHS was conducted by the Kenya National Bureau of Statistics (KNBS) in 2014. The study has been limited to all poor women (women whose wealth index was 'poorest') aged 15-49 in Kenya that were interviewed during the survey. This was done by separating the data by use of SPSS version 20, the women who were categorized as of from household of poorest wealth index. This therefore, created 7,262 Sample of poor women in this study.

\subsection{Dependent Variables}

The dependent / response variable is the binary variable Total number of children ever born by the respondent categorized as under five ( $1=$ below five) and five above, $(2=$ five and above) based on Kenya fertility level of 3.9 (approximately 4) KDHS 2014.

\subsection{Independent Variables}

Predicting whether an event will or will not occur and identifying the variables in making the prediction is an important step in carrying out the study. The independent variables/factors that are used in the study were Age of Respondent, Type of place of residence, Regions of Residence, Education Level, Marital Status, Place of Residence, Contraceptive Use and Desired Family Size.

\subsection{Logistic Regression Model}

Binary Logistic Regression is used to predict the occurrence of socio-economic and demographic impact. In this study, the dependent variable is dichotomous while the predictor variables are categorical and continuous variables. In logit or binary logistic is used. The logistic model is widely used and has many desirable properties [20]. Let $\mathrm{y}_{\mathrm{i}}=1$, less than 5 children ever born and $\mathrm{y}_{\mathrm{i}}=0$ above 5 children ever born $\mathrm{i}=1,2, \ldots, \mathrm{n}$. In the linear logistic regression model the dependency of probability of success on independent variables is assumed to be

$$
\pi\left(x_{i}\right)=P\left(y_{i}=1 / x\right)=\frac{\exp \left(\beta_{0}+\beta_{1} x_{i 1}+\cdots+\beta_{p} x_{i p}\right)}{1+\exp \left(\beta_{0}+\beta_{1} x_{i 1}+\cdots+\beta_{p} x_{i p}\right)}
$$

and the probability of failure is

$$
1-\pi\left(x_{i}\right)=P\left(y_{i}=0 / x\right)=1-\frac{\exp \left(\beta_{0}+\beta_{1} x_{i 1}+\cdots+\beta_{p} x_{i p}\right)}{1+\exp \left(\beta_{0}+\beta_{1} x_{i 1}+\cdots+\beta_{p} x_{i p}\right)}
$$


The logit transformation of the logistic regression model is defined in terms of is as follows:

$$
\lambda_{\mathrm{i}}=\mathrm{g}\left(\mathrm{x}_{\mathrm{i}}\right)=\mathrm{g}\left(\mathrm{x}_{\mathrm{i}}\right)=\frac{\pi\left(\mathrm{x}_{\mathrm{i}}\right)}{1-\pi\left(\mathrm{x}_{\mathrm{i}}\right)}=\beta_{0}+\beta_{1} \mathrm{x}_{\mathrm{i} 1}+\cdots+\beta_{\mathrm{p}} \mathrm{x}_{\mathrm{ip}}
$$

The logit $g(x i)$ is linear in its parameter, continuous and range from $-\infty$ to $+\infty$ depending on the range of $X$ [20]. To evaluate the effectiveness of model, stepwise forward conditional method is also used in the binary logistic regression.

\subsection{Estimation of Parameters and Goodness-of-Fit of the Model}

Estimation of parameters and data analysis of the logistic regression model is normally performed using statistical software. In this study, the $\mathrm{R}$ software environment was used. The $g \operatorname{lm}()$ function, with family= "binomial" option, was used to estimate regression parameters and perform the data analysis. In testing the hypothesis that the model fits the data, the two common approaches are the Pearson's $\chi^{2}$ statistic and the likelihood ratio $G^{2}$ statistic which are based on the comparison of the fitted and the observed counts. The large values of $\chi^{2}$ and $G^{2}$ indicates lack of fit of the observed model. When the fit is poor, residuals and other diagnostic measures describe the influence of individual observations on the model fit and highlight reasons for the inadequacy.

$$
\begin{gathered}
G^{2}=2 \sum(\text { observed }) \log \left(\frac{\text { observed }}{\text { full }}\right)=-2 L L_{R}-\left(-2 L L_{F}\right) \\
=-2 \operatorname{Ln}\left(\frac{\text { Likelihood restricted }}{\text { Likelihood full }}\right)
\end{gathered}
$$

The likelihood ratio is $-2 \ln$ (Likelihood $R$ ) for are smaller model minus $-2 \ln$ (likelihood $F$ ) for a full (larger) model that is the same as the log of the ratio of the two likelihoods, which is distributed as chi-square. The full or larger model has all the parameters of interest in it.

The chi-square is used to statistically test whether including a variable reduces badness-of-fit measure. This is analogous to producing an increment in $\mathrm{R}$-square in hierarchical regression. If chi-square is significant, the variable is considered to be a significant predictor in the equation.

The Pearson's $\chi^{2}=$ statistics is given

$$
\chi^{2}=\sum_{i=1}^{n} \frac{\left(O_{i}-E_{i}\right)^{2}}{E_{i}}
$$

where $\chi^{2}=$ Pearson's cumulative test statistic, which asymptotically approaches a $\chi^{2}$ distribution. $O_{i}=$ an observed frequency, $E_{i}$ =expected frequency asserted by the null hypothesis and $n=$ total frequency.

The Hosmer-Lemeshow test is another alternative in checking model fitness. The test is similar to a $\chi^{2}=$ goodness of fit test and has the advantage of partitioning the observations into groups of approximately equal size, and therefore there are less likely to be groups with very low observed and expected frequencies. The observations are grouped into deciles based on the predicted probabilities. The test statistic is obtained by applying a chi-square test on $2 \mathrm{xg}$ a contingency table. The contingency table is constructed by cross-classifying the dichotomous dependent variable with a grouping variable (with g groups) in which groups are formed by partitioning the predicted probabilities using the percentiles of the predicted event probability. In the calculation, approximately 10 groups are used $(\mathrm{g}=10)$. The corresponding groups are often referred to as the "deciles of risk" [15].

\subsection{Assessing the Goodness of Fit of the Model}

Subsequently fitting a model to a set of data, it is natural to enquire about the extent to which the fitted values of the response variable under the model compare with the observed values. If the agreement between the observations and the corresponding fitted values is good, the model may be acceptable. If not, the current form of model will certainly not be acceptable and the model will need to be revised. This aspect of the adequacy of a model is widely referred to as goodness of fit. To determine the overall significance of a logistic model Likelihood Ratio Test, Classification table and Hosmer and Lemeshow goodness-of-fit test were used. In this study, data were analyzed by using statistical software Statistical package for social sciences (SPSS) Version 16.

\section{Results}

The major Demographic, Socio-economic, and Cultural background characteristics of the respondents are presented in Table 1. The total number of children ever born to women of child bearing age 15 to 49 years is 7,262 . Among these 1,113 reside in urban areas and 6149 reside in urban areas. The majority of women were married 4685 (64.5\%), followed by never and formally married $1522(21.0 \%)$ and living with partner 1055 (14.5\%) respectively). With regard to regional variation of Kenya, greater part of respondents included in this study were from Rift-Valley, Coast and Eastern $(36.1 \%, 19.5 \%$ and $16.6 \%)$ respectively where as smaller part were from Nairobi and Central (0\%and 0.9\%) respectively. With regard to Women Educational level, $42.6 \%$ were No education, primary were about $48.8 \%$ and the remaining $8.5 \%$ belongs to secondary and higher educational level. 
Table 1. The percentage distribution of study population, Total Children Ever Born (TCEB), according to the Socio-demographic and economic variables of poor women in Kenya, 2014 KDHS.

\begin{tabular}{|c|c|c|c|}
\hline Variable & Category & Frequency & Percent \\
\hline \multirow{3}{*}{ Total CEB } & CEB below 5 & 4,638 & 63.9 \\
\hline & CEB 5 and above & 2,624 & 36.1 \\
\hline & Total & 7,262 & 100.0 \\
\hline \multirow{8}{*}{$\begin{array}{l}\text { Age by } \\
\text { Groups }\end{array}$} & $15-19$ & 1,506 & 20.7 \\
\hline & $20-24$ & 1,213 & 16.7 \\
\hline & $25-29$ & 1,376 & 18.9 \\
\hline & $30-34$ & 1,012 & 13.9 \\
\hline & $35-39$ & 924 & 12.7 \\
\hline & $40-44$ & 705 & 9.7 \\
\hline & $45-49$ & 526 & 7.2 \\
\hline & Total & 7,262 & 100.0 \\
\hline \multirow{3}{*}{$\begin{array}{l}\text { Type of place } \\
\text { of residence }\end{array}$} & Urban & 1,113 & 15.3 \\
\hline & Rural & 6,149 & 84.7 \\
\hline & Total & 7,262 & 100.0 \\
\hline \multirow{4}{*}{$\begin{array}{l}\text { Current } \\
\text { Marital Status }\end{array}$} & Never Married & 1,522 & 21.0 \\
\hline & Married & 4,685 & 64.5 \\
\hline & Formerly Married & 1,055 & 14.5 \\
\hline & Total & 7,262 & 100.0 \\
\hline \multirow{9}{*}{ Region } & Coast & 1,416 & 19.5 \\
\hline & North Eastern & 1,019 & 14.0 \\
\hline & Eastern & 1,205 & 16.6 \\
\hline & Central & 67 & .9 \\
\hline & Rift Valley & 2,625 & 36.1 \\
\hline & Western & 327 & 4.5 \\
\hline & Nyanza & 602 & 8.3 \\
\hline & Nairobi & 1 & .0 \\
\hline & Total & 7,262 & 100.0 \\
\hline \multirow{4}{*}{$\begin{array}{l}\text { Education } \\
\text { Level }\end{array}$} & No Education & 3,095 & 42.6 \\
\hline & Primary & 3,547 & 48.8 \\
\hline & Secondary and Higher & 620 & 8.5 \\
\hline & Total & 7,262 & 100.0 \\
\hline \multirow{4}{*}{$\begin{array}{l}\text { Age at First } \\
\text { Birth }\end{array}$} & Age $19 y$ yrs and below & 3,751 & 64.8 \\
\hline & Age $20 y r s$ to $24 \mathrm{yrs}$ & 1,671 & 28.9 \\
\hline & Age above $25 y r s$ & 367 & 6.3 \\
\hline & Total & 5,789 & 100.0 \\
\hline \multirow{4}{*}{$\begin{array}{l}\text { Age at First } \\
\text { Marriage }\end{array}$} & Age 19 and Below & 4,274 & 74.5 \\
\hline & Age 20 to $24 \mathrm{yrs}$ & 1,193 & 20.8 \\
\hline & Age $25 y r s$ and above & 273 & 4.7 \\
\hline & Total & 5,740 & 100.0 \\
\hline \multirow{4}{*}{$\begin{array}{l}\text { Ideal Number } \\
\text { of Children }\end{array}$} & Children 0-2 & 352 & 11.2 \\
\hline & Children 3-5 & 1,454 & 46.1 \\
\hline & Children 6 and above & 1,346 & 42.7 \\
\hline & Total & 3,152 & 100.0 \\
\hline \multirow{4}{*}{$\begin{array}{l}\text { Current } \\
\text { Contraceptive } \\
\text { use by Method } \\
\text { Type }\end{array}$} & No Method & 5,767 & 79.4 \\
\hline & Modern Method & 1,342 & 18.5 \\
\hline & Traditional Method & 153 & 2.1 \\
\hline & Total & 7,262 & 100.0 \\
\hline
\end{tabular}

The chi-square test was adopted at a minimum level of significance for testing the factors associated with fertility differentials. Table 2, presents all explanatory variables have significant effect on an outcome variable at 5\% level of significant. Mothers age at first birth, marital status, Region, Age group, Mother education level are highly statistically significant associated with the TCEB. A mother who is more aware about health care is likely to have fewer children compared to a mother who has no education at all.
Table 2. Cross Tabulation between total CEB and independent variables among poor women in Kenya.

\begin{tabular}{llll}
\hline Variable & Chi-square & df & p-value \\
\hline Age in 5-year groups & $3,512.650$ & 6 & 0.001 \\
Age at First Birth & 5.735 & 2 & 0.057 \\
Age at First Marriage & 14.693 & 2 & 0.001 \\
Region & 36.347 & 7 & 0.001 \\
Type of Place of Residence & 11.570 & 1 & 0.001 \\
Education Level & 325.422 & 2 & 0.001 \\
Current Marital Status & 1004.297 & 2 & 0.001 \\
Contraceptive By Method Type & 23.507 & 2 & 0.001 \\
Ideal Number of Children & 201.663 & 2 & 0.001 \\
\hline
\end{tabular}

The Results of Binary Logistic Regression as displayed in table 3 , the variables that were found to be significant in the multivariate analysis are Region, Women educational level, marital status, age at first cohabitation and age in 5-years group. And this is in effect in line with the results obtained from the univariate analysis. The values of the wald statistic for individual $\beta$ coefficients support that the estimated values $\exp (\hat{\beta})$ for the factors in the final model, their standard error and the odds ratio of each estimated coefficient $(\hat{\beta})$ is also given in the following table generated using forward stepwise procedure. The final logistic regression model includes only those significant variables. From the fitted logistic regression model, the estimates odds ratio displayed in Table 3, for the variable region reference category is Nyanza/Western Region. The value of the odds ratio $\exp (\hat{\beta})=1.0608$, for region that the odds of having TCEB greater than or equal to 5 children for North Eastern region is $6.08 \%$ more than those women in Nyanza/Western Region $(\mathrm{OR}=1.0608, \mathrm{CI}=0.8737$, 1.2879 ) and its statistically significant. The odds of TCEB greater than or equal to 5 has decreased by a factor of 0.6213 in the low fertility region, 0.879 in the coast and 0.8746 in Rift-Valley regions while controlling for other factors. The likelihood of TCEB having greater than or equal to 5 children is 3 times more likely for women who have no education, women with primarily education $(\mathrm{OR}=1.6128, \mathrm{CI}=1.2969$ 2.0057) more than 2 times likely to have more than 5 children in their child bearing age compared with women with secondary or higher education level. This is supported by Adhikari [9] who found that illiterate women have almost double the number of CEB than do literate women. This study further explained education exposes women to information, empowers women, makes them more likely to be employed outside their home environment, and makes them more aware of their own health and the health of their children-all of which are negatively associated with the number of children a woman will have during her reproductive life. Similarly, educated women are more likely to postpone marriage, have smaller family size, and use contraception than are uneducated women [27]. The value of the odds ratio $\exp (\widehat{\beta})=2.0524$, for Age at first birth of the mothers that the odds of having TCEB greater than or equal to 5 children for women age 19 and below is $105.24 \%$ more than those women aged 25 years and above $(\mathrm{OR}=2.0524$, $\mathrm{CI}=1.5872-2.6538)$ and $46.67 \%$ for women aged $20-24$ years. Generally, different studies have established that older age at first marriage played an important role in reduction in 
fertility $[25,30,36,38]$. Similarly the odds ratio $\exp (\hat{\beta})=$ 1.7212 marital status for having TCEB greater than or equal to 5 children is $72.12 \%$ for married women compared to formally married women $(\mathrm{OR}=1.7212, \mathrm{CI}=1.5311-1.9329)$ and its effects is statistically significant. The finding of this study is confirmed by many studies [28, 29, 34] that have found that women that were currently married had more children compared to the not married women. Married women as opposed to unmarried women are highly exposed to frequent sex, thus more likely to have children. In addition, many women marry so as to have children in a family setting.

For the age at first birth, the value of odds ratio is $\exp (\hat{\beta})=6.6061$ for having TCEB greater than or equal to
5 children is $560.61 \%$ women aged 19 year and below more than those aged 25 years and above while the Odds is $143.76 \%$ more for women aged age $20-24$ years at first birth and is statistically significant. This finding is consistence with Ndahindwa et al., [20] who established that in Rwanda, women whose first sexual debut (and in effect age at first birth), was earlier tended to have higher fertility. Additionally, Zaba et. al., [42] established that in Uganda, the interval between first sex and marriage was short; thus women that failed to use contraceptives in their first sex contributed to a high fertility level in the country. In cases where the use of most effective contraceptive methods is absent, usually, the age at first intercourse is close to the age at first birth.

Table 3. Generalized Linear regression results on Total Number of ever Children born and selected socio demographic factors.

\begin{tabular}{|c|c|c|c|c|c|c|c|}
\hline \multirow{2}{*}{ Variable } & \multirow{2}{*}{ Category } & \multirow{2}{*}{$\operatorname{Exp}(\beta)$} & \multicolumn{2}{|l|}{$95 \%$ CI } & \multicolumn{3}{|c|}{ Hypothesis Test } \\
\hline & & & Lower OR & Upper OR & Wald $\chi^{2}$ & df & Sig. \\
\hline \multirow{4}{*}{ Age at First Birth } & (Intercept) & 44.6119 & 32.4597 & 61.2522 & 548.741 & 1 & .000 \\
\hline & Age $19 y$ yrs and below & 6.6061 & 5.2383 & 8.3228 & 255.065 & 1 & .000 \\
\hline & Age $20 \mathrm{yrs}$ to $24 \mathrm{yrs}$ & 2.4376 & 1.9523 & 3.0465 & 61.803 & 1 & .000 \\
\hline & Age above $25 y r s$ & 1.0000 & - & - & . & . & . \\
\hline \multirow{3}{*}{$\begin{array}{l}\text { Age at First } \\
\text { Marriage }\end{array}$} & Age 19 and Below & 2.0524 & 1.5872 & 2.6538 & 29.995 & 1 & .000 \\
\hline & Age 20 to $24 \mathrm{yrs}$ & 1.4667 & 1.1377 & 1.8927 & 8.697 & 1 & .003 \\
\hline & Age $25 y r s$ and above & 1.0000 & - & - & . & . & . \\
\hline Current Marital & Married & 1.7212 & 1.5311 & 1.9329 & 83.752 & 1 & .000 \\
\hline \multirow[t]{2}{*}{ Status } & Formerly Married & 1.0000 & - & - & . & . & . \\
\hline & No Education & 2.3965 & 1.9136 & 3.0042 & 57.563 & 1 & .000 \\
\hline \multirow[t]{4}{*}{ Education Level } & Primary & 1.6128 & 1.2969 & 2.0057 & 18.445 & 1 & .000 \\
\hline & Secondary and Higher & 1.0000 & & & . & . & . \\
\hline & Coast & 0.8790 & 0.7460 & 1.0356 & 2.370 & 1 & .124 \\
\hline & North Eastern & 1.0608 & 0.8737 & 1.2879 & .351 & 1 & .553 \\
\hline \multirow[t]{3}{*}{ Region merged } & Low Fertility Region & 0.6213 & 0.5247 & 0.7364 & 30.286 & 1 & .000 \\
\hline & Rift Valley & 0.8746 & 0.7520 & 1.0171 & 3.037 & 1 & .081 \\
\hline & Nyanza/Western Region & 1.0000 & - & - & . & . & . \\
\hline \multirow{4}{*}{$\begin{array}{l}\text { Age in three } \\
\text { Categories }\end{array}$} & Age below 25 & 0.0062 & 0.0054 & 0.0070 & 6129.958 & 1 & .000 \\
\hline & Age between 25 and 34 & 0.0635 & 0.0573 & 0.0704 & 2755.375 & 1 & .000 \\
\hline & Age 35 and above & 1.0000 & - & - & . & . & . \\
\hline & (Scale) & 16.7266 & 15.0895 & 18.6156 & & & \\
\hline
\end{tabular}

\section{Discussion}

The finding of this study illustrates that the TCEB is statistically significant among women who have no education and primary education. A similar study carried out in Nepal indicates that education exposes women to information, empowers women and makes them more likely to be employed outside their home environment and makes them more aware of their own health and health of their children. Educated women are more likely to postpone marriage, have small family size and use contraceptives more than the uneducated women $[1,10,31]$. We therefore recommended that government and non-governmental agencies should embark on public enlightenment campaign to create awareness on the importance of fertility control. Government should also regulate the age of entry into marital unions. It was recommended among others that public enlightenment campaigns on the use of contraceptives and proper family planning should be embarked upon by concerned agencies.

\section{Conclusion}

One of the socioeconomic development goals (SDGs) to improve maternal health is to ensure universal access to reproductive health, including family planning. Reasons given by the respondents for non-use of contraception suggest that accessibility of family planning services is not a barrier to contraceptive use even among the poorest and it is imperative that other factors must have resulted in the relatively low contraceptive prevalence rate (CPR). The underlying causes for the low usage and high unmet need would have to be further investigated for formulation of program intervention strategies. The 2014 KDHS shows that more than one third of the women mentioned health concern or fear of side effects as a reason for not using a method. Hence, reproductive health information and education are needed to dispel some of the misconceptions in order to increase family planning practice and reduce unmet need for contraception and to enable couples to plan their families according to their financial capability. Socio-economic differentials in fertility can be explained by 
the differential rate of contraceptive use. More efforts are needed to redirect the family planning program to target the disadvantaged groups so that they are able to plan their families according to their financial status. Kenyans entered marriage and gave birth at relatively young age and this may hamper their education and career advancement as well as having adverse effects on their reproductive health. Hence family life and reproductive health education should be introduced in all school levels so as to better the future generation for a planned parenting.

\section{References}

[1] Adhikari, R. (2010). Demographic, Socio-economic, and cultural factors affecting fertility differentials in Nepal. BMC Pregnancy and Childbirth, 10 (19): 1-11.

[2] Alaba, O. O., Olubusoye, O. E., \& Olaomi, J. O. (2017). Spatial patterns and determinants of fertility levels among women of childbearing age in Nigeria. South African Family Practice, 59 (4), 143-147.

[3] Anyara, E. L. \& Hinde, A. (2006). Fertility transition in Kenya: A regional analysis of the proximate determinants. Applications \& Policy Working Paper A06/0 (2006). Southampton Statistical Sciences Research Institute.

[4] Awes, A. A. (2014). Proximate Determinants of Fertility among Poor and Non-poor Women in Kenya. Unpublished MSc Research project in Population studies, University of Nairobi.

[5] Bongaarts, J. (1984). A simple method for estimating the contraceptive prevalence required to reach a fertility target. Studies in Family Planning, 15 (4): 184-90.

[6] Bongaarts, J. (1978). A Framework for Analyzing the Proximate Determinants of Fertility. Population and Development Review, 4, pp. 105-131.

[7] Bongaarts, J. and Casterline, J. (2012). Fertility Transition: Is sub-Saharan Africa Different? Population and Development review 38 (Supplement): 153-168.

[8] Caldwell J. (1992). Fertility decline in Africa: A new type of transition? Population and Development Review, 18 (2): 211242 .

[9] Caldwell, J. C. (2005). On net intergenerational wealth flows: An update. Population and Development Review 31 (4): 721740.

[10] Desalegn Dargaso Dana (2018). Binary Logistic Regression Analysis of Identifying Demographic, Socioeconomic, and Cultural Factors that Affect Fertility among Women of Child bearing Age in Ethiopia. Science Journal of Applied Mathematics and Statistics. Vol. 6, No. 3, 2018, pp. 65-73. doi: 10.11648/j.sjams.20180603.11.

[11] Dube J., Tariku, D., and Mohammed, T. (2013). Determinants of High Fertility Status among Married Women in Gilgel Gibe Field Research Center of Jimma University, Oromia, Ethiopia: A Case Control Study"- Published online at http://journal.sapub.org/phr Copyright Scientific \& Academic Publishing.

[12] Dutta, P. \& Sarkar, S. (2014). Trend and Differentials of a
Socio-Demographic Scenario and Extent of Adolescent Fertility in Maharashtra, India. Journal of Settlement and Spatial Planning, 5 (1): 31-47.

[13] Gomes, C. (2012). Adolescent fertility in selected countries of Latin America and Caribbean. Journal of Public Health and Epidemiology, 4 (5): 133-140.

[14] Gupta, N. \& Mahy, M. (2003). Adolescent childbearing in sub-Saharan Africa: Can increased schooling alone raise ages at first birth? Demographic Research, 8 (4): 93-106.

[15] Hosmer, David W., Scott Taber, and Stanley Lemeshow. "The importance of assessing the fit of logistic regression models: a case study." American journal of public health 81, no. 12 (1991): 1630-1635.

[16] Kenya National Bureau of Statistics and ICF Macro (2015). 2014 Kenya Demographic and Health Survey: Key Findings. Calverton, Maryland, USA: KNBS and ICF Macro.

[17] LaValley, M. P. (2008). Statistical Primer for Cardiovascular Research: Logistic Regression. Journal of American Heart Association 117: 2395-2399.

[18] Lerch, M. (2019). Regional variations in the rural-urban fertility gradient in the global South. PLOS ONE, 14 (7), e0219624.

[19] Letamo, G. and Letamo, H. (2002). The Role of Proximate Determinants in Fertility Transition: A Comparative Study of Botswana, Zambia, and Botswana. SA Journal of Demography, 8 (1): 29-35.

[20] McCullagh, P. and Nelder, J. A. (1989) Generalized Linear Models, Chapman and Hall, London.

[21] Martin, T. C. (1995). Women's education and fertility: Result from 26 demographic and health surveys. Study in Family Planning, 26 (4): 187-202.

[22] Masanja, G. F. (2014). Rural-urban residence, modernism and fertility: a study of Mwanza region, Tanzania. African Population Studies, 28 (3), 1399-1412.

[23] Majumder, N., \& Ram, F. (2015). Explaining the role of proximate determinants on fertility decline among poor and non-poor in Asian countries. PloS one, 10 (2), e0115441.

[24] Muhoza, D. N., Broekhuis, A., \& Hooimeijer, P. (2014). Variations in desired family size and excess fertility in East Africa. International journal of population research, 2014.

[25] Nargund, G. (2009). Declining birth rate in Developed Countries: A radical policy re-think is required. Facts, views \& vision in ObGyn, 1 (3), 191.

[26] NCPD (2013). Kenya Population situation analysis. Nairobi: Government of Kenya.

[27] Ndahindwa et al. (2014). Determinants of fertility in Rwanda in the context of a fertility transition: a secondary analysis of the 2010 Demographic and Health Survey". Reproductive Health, 11: 87.

[28] Nwogwugwu, N. C. (2013). Socio-Demographic Determinants of Adolescent Fertility in Zambia. Student Thesis. University of the Witwatersrand, Johannesburg.

[29] Nyarko, S. H. (2012). Determinants of Adolescent Fertility in Ghana. International Journal of Sciences: Basic and Applied Research (IJSBAR), 5 (1): 21-32. 
[30] Okech, T. C., Wawire, N. W., \& Mburu, T. K. (2011). Contraceptive use among women of reproductive age in Kenya's city slums. International Journal of Business and Social Science, 2 (1): 22-43.

[31] Omariba, D. W. R. (2006). Women's educational attainment and intergenerational patterns of fertility behaviour in Kenya. Journal of biosocial science, 38 (4), 449-479.

[32] Onoja M, and Osayomore, I. (2012). Modeling the Determinants of Fertility among Women of Childbearing Age in Nigeria: Analysis Using Generalized Linear Modeling Approach. International Journal of Humanities and Social Science Vol. 2 No. 18.

[33] Retherford, R. D. and Thapa, S. (2003). Fertility in Nepal, 1981-2000: Level, trend, and component of change. Population and Health Series, No. 111.

[34] Rutaremwa, G. (2013). Factors associated with adolescent pregnancy and fertility in Uganda: analysis of the 2011 demographic and health survey data. Social Sciences, 2 (1): 7 13.

[35] Rutstein, S. O. and Kiersten J. (2004). "The DHS wealth index" DHS Comparative Reports No. 6. Calverton, Maryland, USA, ORC Macro.

[36] Serbessa, D. D. (2003). Differential impact of women's educational level on fertility in Africa: The case of Ethiopia. Addis Ababa.

[37] Shapiro, D., \& Tambashe, O. (2000). Fertility transition in urban and rural areas of Sub-Saharan Africa. Population Research Institute, Pennsylvania State University.

[38] Sibanda, A., Woubalem, Z., Hogan, D. P. and Lindstrom, D. P. (2003). The proximate determinants of the decline to belowreplacement fertility in Addis Ababa, Ethiopia. Studies in Family Planning, 34 (1): 1-7.

[39] Schultz, T. Paul (2005), "Fertility and Income" Yale University Economic Growth Center Discussion Paper No. 925.

[40] Timothy C. Okech, Dr. Nelson W. Wawire, Dr. Tom K. Mburu (2011). Contraceptive Use among Women of Reproductive Age in Kenya's City Slums. International Journal of Business and Social Science, 2 (1): 22-43.

[41] Wasao, S. (2001). "A Comparative Analysis of the Socioeconomic Correlates of Fertility in Cameroon and the Central African Republic". A paper presented at the Workshop on Prospects for Fertility Decline in High Fertility Countries, New York, 9-11 July 2001.

[42] Zaba, B., Pisani, E., Slaymaker, E. \& Ties Boerma, J. (2004). Age at first sex: understanding recent trends in African demographic surveys. Sexually Transmitted Infection, 80: 2835 .

[43] Zubairu Iliyasu, Hadiza S. Galadanci, Alfa I. Oladimeji, Musa Babashani, Auwalu U. Gajida, Muktar H. Aliyu. (2019) Predictors of Safer Conception Practices Among HIV-Infected Women in Northern Nigeria. International Journal of Health Policy and Management 8: 8, pages 480-487. 